\title{
Morphology of Acetabulum and Femoral Head-Neck Junction in Hip Dysplasia Which Underwent Rotational Acetabular Osteotomy
}

Ryo Kanto, Hiroshi Nakayama, Shoji Nishio, Yuki Fujihara, Yu Takeda, Shigeo Fukunishi, Shinichi Yoshiya, Toshiya Tachibana

Department of Orthopaedic Surgery, Hyogo College of Medicine, Nishinomiya, Japan

Email: ryokanto710@gmail.com

Received 16 April 2015; accepted 18 May 2015; published 21 May 2015

Copyright (C) 2015 by authors and Scientific Research Publishing Inc.

This work is licensed under the Creative Commons Attribution International License (CC BY).

http://creativecommons.org/licenses/by/4.0/

(c)

\section{Abstract}

The purpose of this study was to evaluate the preoperative radiographs with cases of developmental dysplasia of the hip (DDH) leading to rotational acetabular osteotomy (RAO) or curved peri-acetabular osteotomy (CPO), and examine the frequency of femoroacetabular impingement (FAI) related bone morphology in the acetabulum and femoral head-neck junction. Twenty-four hips with hip dyaplasia who underwent CPO or RAO were included in this study. Six hips had grade 0 and eighteen hips had grade $1 \mathrm{OA}$ according to the Tönnis classification. We excluded patients with moderate and severe hip osteoarthritis and major femoral head deformities. Preoperative radiograph was evaluated on sharp angle, center-edge angle, alpha angle, crossover sign and posterior wall sign. Crossover signs were revealed in 7 hips $(29.2 \%)$; posterior wall signs were revealed in 16 hips (66.7\%); and cam-type deformities with an alpha angle of $\geq 50.5^{\circ}$ were observed in 19 hips (79.2\%) in preoperative evaluation. As determined using the Tönnis scale, no progression of osteoarthritis was found in 16 of the 24 hips; there was a one-grade progression in 8 hips. Among the 8 hips, either positive cross-over sign or posterior sign in acetabulum, and an alpha angle of $\geq 50.5^{\circ}$ in femur were observed in six hips with progression of osteoarthritis. The presence of cam-type deformity and acetabular retroversion in patients who underwent RAO or CPO was relatively high in preoperative radiographs, and caution should be employed during surgery in patients with DDH. There is a possibility of secondary FAI due to excessive forward coverage of the bone fragments after RAO and CPO. 


\section{Keywords}

\section{Acetabular Hip Dysplasia, Acetabular Osteotomy, Femoroacetabular Impingement}

\section{Introduction}

Femoroacetabular impingement (FAI) and developmental dysplasia of the hip (DDH) are major etiological factors in the development of osteoarthritis (OA) of the hip.

The pathomechanism of FAI is a dynamic condition caused by an altered osseous morphology of the acetabulum or femoral head-neck junction [1]-[3]. Two types of FAI can be distinguished: cam impingement and pincer impingement. Pincer impingement is caused by over coverage of the acetabulum relative to the femoral head, and cam impingement is caused by extra bone formation in the anterolateral head-neck junction.

In recent epidemiological studies, the significance of acetabular retroversion in DDH associated with FAI has been addressed [4]-[7]. FAI is thought to be associated with the pathology of DDH, but not much has been published about the morphological characteristics of the acetabulum and femoral head-neck junction in patients with hip dysplasia. This concept is important, because acetabular malpositioning after osteotomy may lead to an iatrogenic pincer type of impingement, especially in cases with lateral over coverage or retroversion [8]-[10]. In addition, an aspherical femoral head in DDH [11] will increase the risk of secondary cam-type FAI that is reportedly symptomatic in 22/46 (47.8\%) hips after reorientation [7]. These mechanisms seem to be involved in secondary lesions of the acetabular labrum tear and the articular cartilage damage of the acetabulum, with subsequent development of OA. Several studies suggest that even mild cam-type deformities can significantly lead to secondary OA of the hip [1].

The purpose of this study was to evaluate the preoperative radiographs with cases of DDH leading to rotational acetabular osteotomy (RAO) or curved periacetabular osteotomy (CPO) [12] retrospectively, and examine the frequency of FAI related bone morphology in the acetabulum and femoral head-neck junction.

\section{Material and Method}

This study design was approved by Institutional Review Board of Hyogo College of Medicine.

We performed a retrospective examination of pre- and postoperative radiographs on 24 hips in 23 patients, which included 22 females and 1 male, who were underwent acetabular osteotomy. We have improved and changed surgical procedure since 2009. Therefore, osteotomy was performed on 10 hips with RAO and 14 hips with CPO between December 2004 and December 2012. Osteotomy was performed with the RAO from December 2004 to February 2009, and with the CPO from February 2009 to December 2012. The mean age of these patients upon presentation was 30.8 years (ranged 19 to 44 years). Minimum follow up periods are 2 years after surgery. The Tönnis classification was used to grade the extent of OA [13] [14]. Six hips had grade 0, and eighteen hips had grade $1 \mathrm{OA}$ according to the Tönnis classification system. We excluded patients with moderate and severe hip osteoarthritis (Tönnis grade 2 and 3) and major femoral head deformities such as typical capital drop deformity, Perthes' disease, or slipped capital femoral epiphysis (SCFE). All of the patients including in this study were diagnosed with dysplasia. The surgical indications for RAO and CPO included symptomatic acetabular dysplasia under the age of $45^{\circ}$, a lateral center-edge (CE) angle of less than $20^{\circ}$ and a Sharp angle of greater than $45^{\circ}$ on anteroposterior (AP) radiographs (Figure 1), and the improvement of joint congruency on an AP radiograph in the abducted position. The radiological assessment of potential cam-type deformity was based on the measurement of the alpha angle on the cross-table lateral view. It was measured by first drawing the best fitting circle around the femoral head, then a line through the center of the neck and the center of the head. From the center of the femoral head a second line was drawn to the point where the superior surface of the head-neck junction first departs from the circle. The angle between these two lines is the alpha-angle (Figure 2). Several studies have defined the upper limit of normal for the alpha angle as being 50.5 [1] [15], and we applied the cut-off angle of more than $50.5^{\circ}$ to define cam impingement deformity [1]. On the AP pelvic radiograph, Sharp angle, CE angle, crossover sign, and posterior wall sign [16] (Figure 3) were evaluated. Acetabular retroversion was defined as the presence of a crossover sign [16]-[18].

All of these signs are sensitive to the position of the pelvis relative to the plane of the X-ray beam and an as 


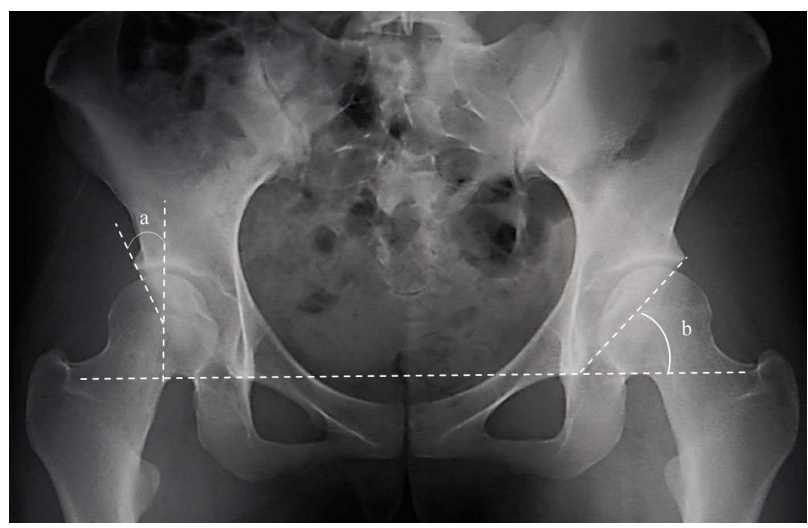

Figure 1. Radiographic presentation of (a) lateral center-edge (CE) angle and (b) sharp angle on AP view.

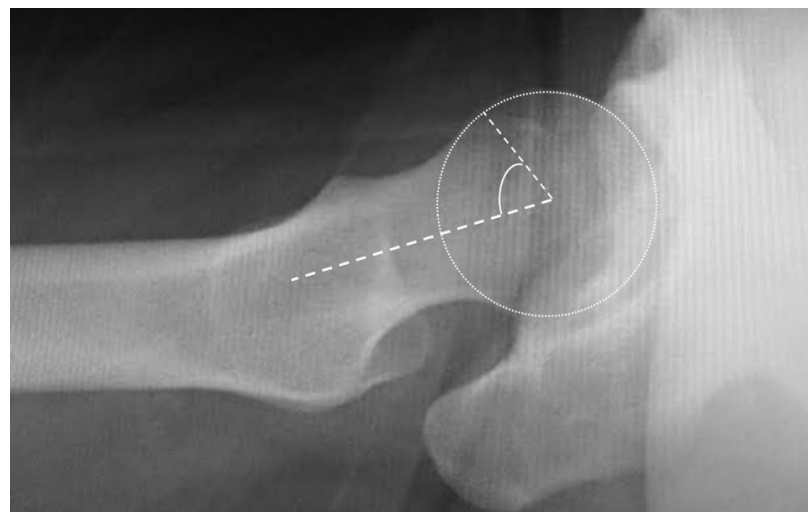

Figure 2. Radiographic presentation of the alpha angle on the cross-table lateral view. The angle was measured by first drawing the best fitting circle around the femoral head, then a line through the center of the neck and the center of the head. From the center of the femoral head a second line was drawn to the point where the superior surface of the head-neck junction first departs from the circle. The angle between these two lines is the alpha-angle.

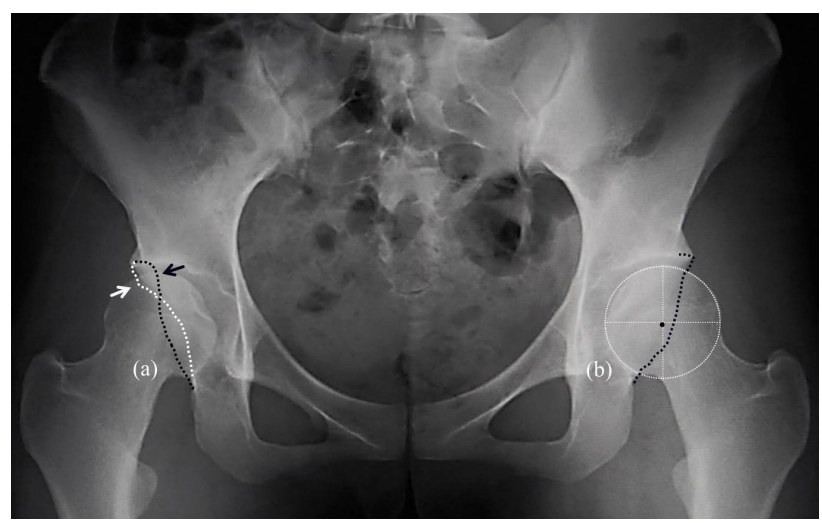

Figure 3. (a) Radiographic presentation of acetabular retroversion is defined as anteior wall being more lateral than posterior wall. the cross over sign with the black dotted line depicting the posterior wall and the white dotted line the anterior wall; (b) Radiographic presentation of the posterior wall sign with the black dotted line depicting the posterior wall running laterally to femoral head center. 
sessment of this was undertaken. Rotation was checked by confirming the alignment of the coccyx and symphysis pubis. The extent of the pelvic inclination was judged according to a previously described method [19]. The distance between the pubic symphysis and sacrococcygeal joint was measured on each standard AP radiograph for comparison with the reported control values of 25 - $40 \mathrm{~mm}$ for men and 40 - $55 \mathrm{~mm}$ for women [19]. All of the radiographs were assessed by a single reviewer (R.K). Patients whose preoperative radiograph did not fulfill these criteria were excluded from this study.

\section{Results}

The results of the preoperative measurements were as follows: Sharp angle $49.5^{\circ} \pm 2.5^{\circ}$, CE angle $9.5^{\circ} \pm 7.2^{\circ}$, and alpha-angle $67.6^{\circ} \pm 18.9^{\circ}$ (Table 1 , Table 2). Crossover signs were revealed in 7 hips (29.2\%) and posterior wall signs in 16 hips (66.7\%). Cam-type deformities with an alpha angle of $\geq 50.5^{\circ}$ were observed in 19 hips (79.2\%) (Table 3). Of these 19 hips with cam-type deformities of $\geq 50.5^{\circ}, 13$ hips (54.2\%) had an alpha angle of $\geq 70^{\circ}$ and 6 hips (25.0\%) had an alpha angle of $\geq 80^{\circ}$ (Figure 4). Additionally, combined deformities both acetabulum and femoral head-neck junction were observed in 14 hips (58.3\%), which was revealed either positive cross over sign or posterior wall sign in acetabulum and an alpha angle of $\geq 50.5^{\circ}$ in femur. DDH related deformity were improved after surgery with Sharp angle $37.1^{\circ} \pm 4.9^{\circ}$ and CE angle $32.9^{\circ} \pm 9.9^{\circ}$ in postoperative

Table 1. Pre- and postoperative radiographic status of all patients.

\begin{tabular}{|c|c|c|c|c|c|c|c|c|c|c|}
\hline \multirow{2}{*}{ Patients } & \multirow{2}{*}{ Age } & \multirow{2}{*}{ Sex } & \multicolumn{2}{|c|}{ Sharp angle $\left(^{\circ}\right)$} & \multicolumn{2}{|c|}{ CE angle $\left({ }^{\circ}\right)$} & \multirow{2}{*}{ Crossover sign } & \multirow{2}{*}{ Posterior wall sign } & \multirow{2}{*}{ Alpha-angle ( ${ }^{\circ}$ ) } & \multirow{2}{*}{ Tönnis grade } \\
\hline & & & pre & post & pre & post & & & & \\
\hline 1 & 34 & $\mathrm{~F}$ & 50 & 35 & 15 & 40 & + & - & 47 & 1 \\
\hline 2 & 35 & $\mathrm{~F}$ & 50 & 42 & 10 & 25 & - & + & 95 & 1 \\
\hline 3 & 26 & $\mathrm{~F}$ & 45 & 35 & 19 & 46 & - & + & 55 & 1 \\
\hline 4 & 27 & $\mathrm{~F}$ & 47 & 41 & 15 & 39 & - & - & 76 & 1 \\
\hline 5 & 33 & $\mathrm{~F}$ & 50 & 32 & 0 & 40 & - & + & 35 & 1 \\
\hline 6 & 35 & $\mathrm{~F}$ & 50 & 37 & 2 & 32 & - & + & 110 & 1 \\
\hline 7 & 32 & $\mathrm{~F}$ & 47 & 32 & 15 & 39 & + & + & 81 & 1 \\
\hline 8 & 37 & $\mathrm{~F}$ & 55 & 37 & -10 & 13 & - & - & 35 & 1 \\
\hline 9 & 28 & F & 48 & 40 & 15 & 50 & + & + & 73 & 0 \\
\hline 10 & 23 & F & 54 & 47 & 4 & 16 & - & + & 83 & 1 \\
\hline 11 & 23 & $\mathrm{M}$ & 51 & 36 & 8 & 33 & - & - & 71 & 1 \\
\hline 12 & 44 & F & 52 & 36 & 3 & 27 & - & + & 96 & 1 \\
\hline 13 & 35 & F & 51 & 46 & 4 & 20 & - & + & 49 & 1 \\
\hline 14 & 42 & F & 48 & 40 & 16 & 25 & + & + & 42 & 1 \\
\hline 15 & 42 & F & 51 & 43 & -2 & 32 & - & + & 58 & 1 \\
\hline 16 & 24 & F & 46 & 30 & 6 & 39 & - & + & 53 & 0 \\
\hline 17 & 24 & $\mathrm{~F}$ & 48 & 31 & 16 & 50 & - & + & 63 & 0 \\
\hline 18 & 42 & F & 51 & 33 & 5 & 23 & - & - & 78 & 1 \\
\hline 19 & 24 & F & 52 & 41 & 16 & 31 & + & - & 74 & 1 \\
\hline 20 & 22 & $\mathrm{~F}$ & 50 & 34 & 16 & 30 & - & + & 61 & 1 \\
\hline 21 & 31 & F & 48 & 39 & 15 & 40 & - & - & 57 & 1 \\
\hline 22 & 23 & F & 52 & 30 & 8 & 41 & - & - & 83 & 0 \\
\hline 23 & 35 & F & 47 & 40 & 16 & 35 & + & + & 70 & 0 \\
\hline 24 & 19 & F & 45 & 34 & 15 & 31 & + & + & 77 & 0 \\
\hline
\end{tabular}

$(+)$ = positive, $(-)=$ negative . 
Table 2. Pre- and postoperative radiographic measurements of the acetabulum and femoral head.

\begin{tabular}{ccc}
\hline \multirow{2}{*}{$\mathrm{n}=24$ hips } & \multicolumn{2}{c}{ Mean angle $\left(^{\circ}\right)$ (SD; range) } \\
\cline { 2 - 3 } & Preoperative & Postoperative \\
\hline Sharp angle & $49.5(2.5 ; 45$ to 55$)$ & $37.1(4.9 ; 30$ to 47$)$ \\
CE angle & $9.5(7.2 ;-10$ to 19$)$ & $32.9(9.9 ; 13$ to 50$)$ \\
Alpha-angle & $67.6(18.9 ; 35$ to 110$)$ & \\
\hline
\end{tabular}

Table 3. Prevalence of crossover sign, posterior wall sign, and cam-type deformity in preoperative radiographs.

\begin{tabular}{ccc}
\hline $\mathrm{n}=24$ hips & Positive & Percentage \\
\hline Crossover sign & 7 & $29.2 \%$ \\
Posterior wall sign & 16 & $66.7 \%$ \\
Cam-type deformity (alpha-angle $\geq 50.5^{\circ}$ ) & 19 & $79.2 \%$ \\
\hline
\end{tabular}

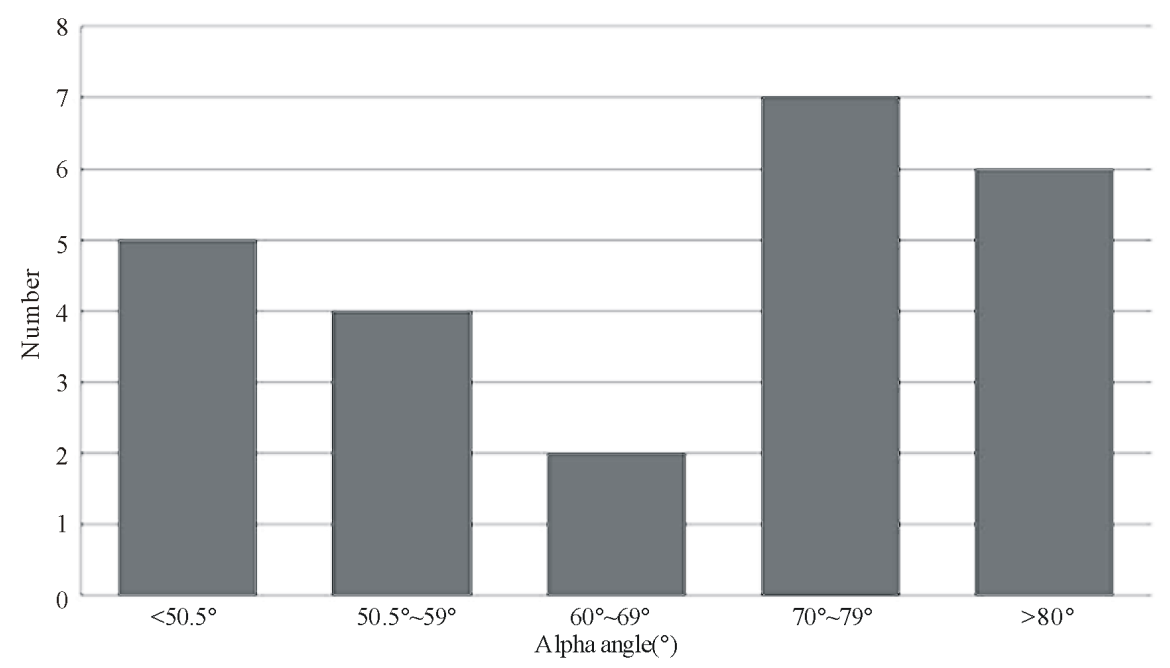

Figure 4. The number distribution of alpha angle. Cam-type deformities with an alpha angle of $\geq 50.5^{\circ}$ were observed in 19 hips (79.2\%). Of these 19 hips with cam-type deformities of $\geq 50.5^{\circ}$, 13 hips (54.2\%) had an alpha angle of $\geq 70^{\circ}$ and 6 hips (25.0\%) had an alpha angle of $\geq 80^{\circ}$.

radiograph. As determined using the Tönnis scale, no progression of osteoarthritis was found in 16 of the 24 hips, there was a one-grade progression in 8 hips. Among, 6 of 8 hips (75\%) with progression of osteoarthritis were observed either positive cross over sign or posterior wall sign and an alpha angle of $\geq 50.5^{\circ}$ (Table 4 ).

\section{Discussion}

The prevalence of acetabular retroversion in the normal population as well as patients with hip disorders has been previously investigated [4] [5]. Fujii et al. [4] reported acetabular retroversion in 17 of the 96 hips (18\%) of patients with DDH. Also, Ezoe et al. [5] reported the prevalence in 18\% (13 of 74 hips) of DDH patients as compared to $6 \%$ (7 of 112 hips) in normal subjects. Compared with previous literatures, the background of the patients in this study could be possible severe DDH with Sharp angle $49.5^{\circ} \pm 2.5^{\circ}$ and CE angle $9.5^{\circ} \pm 7.2^{\circ}$, which need rotational osteotomy. The incidence of the preoperative retroversion in this study was relatively high (29.2\%). Additionally, 18 hips (75\%) were defined as acetabular side deformity under the hypothetical situation of either positive cross over sign or posterior wall sign. Regarding the surgical treatment for DDH, various forms of periacetabular osteotomy have been proposed and reported with their surgical outcome [12] [20]. Al- 
though these procedures can effectively improve lateral coverage of the femoral head, inadvertent post-operative acetabular retroversion has also been reported [6] [10] [21]. Myers et al. [10] reported five cases presenting anterior FAI caused by acetabular retroversion following the Bernese periacetabular osteotomy. Xie et al. [6] evaluated patients with DDH who underwent CPO and found acetabular retroversion in 16 (15\%) of 106 hips preoperatively, while the postoperative evaluations showed $66(62 \%)$ hips with acetabular retroversion. The evaluation of acetabular version revealed that 50 of 106 hips (47\%) with preoperative anteversion were overcorrected to retroversion. Additionally, 14 hips had progressed arthrosis, and 10 of the 14 hips (71\%) with progression of arthrosis showed positive crossover sign. Furthermore, Kiyama et al. [21] reported that 5 of 24 hips (24\%) with acetabular retroversion following CPO were complicated with post-operative progression of osteoarthritis. On the other hand, Yasunaga et al. [7] reported that the rate of cases with a positive crossover sign showed an increase after RAO from $7.8 \%$ before surgery to $42.6 \%$ after surgery. Despite this, most of the cases with a positive crossover sign also showed a positive impingement sign; however, a positive cross over sign was not involved with the progression of arthrosis. Additionally, preoperative CT was necessary for the preoperative planning for osteotomy, we also examined the Preoperative CT for all patients including in the present study. However, no papers have been described the definition to quantify the retroversion and Cam type deformity by CT evaluation. Accordingly, we only evaluated the each parameter in the plain radiograph in the present study.

In addition, a high incidence of an impingement sign after PAO has been reported (24\% - 47.8\%) [8] [22] [23] (Table 5), however, the literatures have not mentioned an association with progression of OA, impingement sign, alpha angle, and crossover sign. Regarding cam-type deformity, Hack et al. [24] reported that deformity with an alpha angle of $\geq 50^{\circ}$ was noted in $24.7 \%$ and $5.4 \%$ of the hips of healthy male and female volunteers, respectively. In Japanese patients, Mori et al. [25] reported the prevalence of cam type deformity (alpha angle $\geq 50.5^{\circ}$ ) with Tönnis grade 0 and 1 . They reported that 29 of 202 hips (14.1\%) had cam type deformity. In our present study, the incidence of cam-type deformity was relatively high (19 of 24 hips 79.2\%). In particular, the distribution of the alpha angle showed angles of $\geq 80^{\circ}$ were present in $6(25.0 \%)$ of 19 hips with an alpha angle of $\geq 50.5^{\circ}$ in DDH patients.

Regarding the relationship between cam-type deformity and progression of OA, Agricola et al. [26] reported that the odds ratio of progression to end stage OA within 5 years with an alpha angle of $\geq 60^{\circ}$ and $\geq 83^{\circ}$ was 3.67 and 9.66, respectively, and concluded that alpha angle was strongly related to the progression of OA. Considering this report, correcting DDH without treatment of cam-type deformity may lead to be could be the risk of

Table 4. Relationship between preoperative morphology and progression of osteoarthritis.

\begin{tabular}{cccc}
\hline \multirow{2}{*}{ Patients } & \multicolumn{2}{c}{ Tönnis grade } & Type of deformity \\
\cline { 2 - 3 } & Preoperative & Postoperative & Cam \\
\hline 4 & 1 & 2 & - \\
9 & 1 & 2 & Both \\
10 & 0 & 1 & Both \\
12 & 1 & 2 & Both \\
15 & 1 & 2 & Both \\
16 & 1 & 2 & Both \\
17 & 0 & 1 & Both \\
\hline
\end{tabular}

Table 5. Previous report of secondary impingement in studies evaluating follow up of PAO.

\begin{tabular}{ccccc}
\hline Author & Year & Hips & Follow up (years) & Impingement sign (\%) \\
\hline Siebenrock et al. [22] & 1999 & 75 & 11 & 29 \\
Steppacher et al. [23] & 2008 & 58 & 19 & 38 \\
Ziebarth et al. [8] & 2010 & 46 & 3.5 & 47 \\
\hline
\end{tabular}


progression of OA. In a recent report, Christoph et al. [27] evaluated proper acetabular reorientation and the creation of a spherical femoral head to improve long-term survivorship and decelerate OA progression in patients with DDH. In our present study, the presence of cam-type deformity in patients who underwent RAO or $\mathrm{CPO}$ was relatively high in preoperative radiographs. In addition, combined FAI related bone morphology in the acetabulum and femoral head-neck junction were showing either positive cross over sign or posterior wall sign and an alpha angle of $\geq 50.5^{\circ}$ in 14 hips (58.3\%), among 6 of these 14 hips (42.8\%) were progressed OA grade. The morphologic features of the femoral head may lead to progression of OA without optimal acetabular orientation, which is meant to provide the best reasonable orientation given the anatomic constraints and corrected spherical femoral head. Currently, to prevent secondary FAI, we have been performing endoscopic osteochondroplasty before $\mathrm{CPO}$ for the cases with an alpha angle of $\geq 50.5^{\circ}$ in preoperative radiograph [28].

This study has several limitations. First, this retrospective study included a small sample size and lacked a control group with normal hips. Second, intraobserver reliability was not reported. Previous reports showed a poor correlation between the intraobserver reporting of the crossover sign and alpha-angle [29]. Third, our study did not evaluate pre- and postoperative physical examination. Finally, we could not evaluate the post-operative radiological result with long-term follow up, our minimum follow up periods are 2 years after surgery. In a future study we need to evaluate the relationship between the physical examination and radiological findings, and a long term follow up about progression of OA is also necessary.

\section{Conclusion}

We evaluated the morphological variables in patients with hip dysplasia who underwent rotational acetabular osteotomy. The results of this study support the hypothesis that there are differences in the morphology of the proximal femur and acetabulum in patients with hip dysplasia who underwent RAO and CPO compared to normal hips. Especially, the presence and severity of cam-type deformity were relatively higher in preoperative radiographs than other previous reports. There is a possibility of secondary FAI due to excessive forward coverage of the rotated/moved bone fragments and cam-type deformity after RAO and CPO, which is involved with the progression of OA. Therefore, secondary FAI should be prevented by adding to surgical methods with careful consideration of these findings.

\section{Conflict of Interest}

The authors claim that there exist no conflicts of interest.

\section{References}

[1] Notzli, H.P., Wyss, T.F., Stoecklin, C.H., Schmid, M.R., Treiber, K. and Hodler, J. (2002) The Contour of the Femoral Head-Neck Junction as a Predictor for the Risk of Anterior Impingement. The Journal of Bone and Joint Surgery (British Volume), 84, 556-560. http://dx.doi.org/10.1302/0301-620X.84B4.12014

[2] Audenaert, E.A., Peeters, I., Vigneron, L., Baelde, N. and Pattyn, C. (2012) Hip Morphological Characteristics and Range of Internal Rotation in Femoroacetabular Impingement. The American Journal of Sports Medicine, 40, 13291336. http://dx.doi.org/10.1177/0363546512441328

[3] Ganz, R., Parvizi, J., Beck, M., Leunig, M., Notzil, H. and Siebenrock, K.A. (2003) Femoroacetabular Impingement: A Cause for Osteoarthritis of the Hip. Clinical Orthopaedics and Related Research, 417, 112-120.

[4] Fujii, M., Nakashima, Y., Yamamoto, T., Mawatari, T., Motomura, G., Matsushita, A., Matsuda S., Jingushi, S. and Iwamoto, Y. (2010) Acetabular Retroversion in Developmental Dysplasia of the Hip. The Journal of Bone and Joint Surgery (American Volume), 92, 895-903. http://dx.doi.org/10.2106/JBJS.I.00046

[5] Ezoe, M., Naito, M. and Inoue, T. (2006) The Prevalence of Acetabular Retroversion among Various Disorders of the Hip. The Journal of Bone and Joint Surgery (American Volume), 88, 372-329. http://dx.doi.org/10.2106/JBJS.D.02385

[6] Xie, J., Naito, M. and Maeyama, A. (2010) Evaluation of Acetabular Version after Curved Periacetabular Osteotomy for Dysplasic Hip. International Orthopaedics, 34, 473-477. http://dx.doi.org/10.1007/s00264-009-0785-2

[7] Yasunaga, Y., Yamasaki, T., Matsuo, T., Ishikawa M., Adachi, N. and Ochi, M. (2010) Cross over Sign Rotational Acetabular Osteotomy for Dysplasia of the Hip. Journal of Orthopaedic Science, 15, 463-469. http://dx.doi.org/10.1007/s00776-010-1489-6

[8] Ziebarth, K., Balakumar, J. and Domayer, S. (2011) Bernese Periacetabular Osteotomy in Males Is There an Increased Risk of Femoroacetabular Impingement (FAI) after Bernese Periacetabular Osteotomy? Clinical Orthopaedics and 
Related Research, 469, 447-453. http://dx.doi.org/10.1007/s11999-010-1544-9

[9] Clohisy, J.C., Nunley, R.M., Carlisle, J.C. and Schoenecker, P.L. (2009) Incidence and Characteristics of Femoral Deformities in the Dysplastic Hip. Clinical Orthopaedics and Related Research, 467, 128-134. http://dx.doi.org/10.1007/s11999-008-0481-3

[10] Myers, S.R., Eijer, H. and Ganz, R. (1999) Anteriorfemoroacetabular Impingement after Periacetabular Osteotomy. Clinical Orthopaedics and Related Research, 363, 93-99. http://dx.doi.org/10.1097/00003086-199906000-00012

[11] Steppacher, S.D., Tannast, M., Werlen, S. and Siebenrock, K.A. (2008) Femoral Morphology Differs between Deficient and Excessive Acetabular Coverage. Clinical Orthopaedics and Related Research, 466, 782-790. http://dx.doi.org/10.1007/s11999-008-0141-7

[12] Naito, M., Shiramizu, K., Akiyoshi, Y., Ezoe, M. and Nakamura, Y. (2005) Curved Periacetabular Osteotomy for Treatment of Dysplastic Hip. Clinical Orthopaedics and Related Research, 433, 129-135. http://dx.doi.org/10.1097/01.blo.0000153281.75265.1d

[13] Tönnis, D. (1976) Normal Values of the Hip Joint for the Evaluation of X-Rays in Children and Adults. Clinical Orthopaedics and Related Research, 119, 39-47.

[14] Tönnis, D. and Heinecke, A. (1999) Acetabular and Femoral Anteversion: Relationship with Osteoarthritis of the Hip. The Journal of Bone and Joint Surgery (American Volume), 81, 1747-1770.

[15] Beaule, P.E., Zaragoza, E.J., Motamedic, K., Copelan, N. and Dorey, F.J. (2005) Three-Dimensional Computed Tomography of the Hip in the Assessment of Femoro-Acetabular Impingement. Journal of Orthopaedic Research, 23, 1286-1292. http://dx.doi.org/10.1016/j.orthres.2005.03.011.1100230608

[16] Reynolds, D., Lucas, J. and Klaue, K. (1999) Retroversion of the Acetabulum: A Cause of Hip Pain. The Journal of Bone and Joint Surgery (British Volume), 81, 281-288. http://dx.doi.org/10.1302/0301-620X.81B2.8291

[17] Jamali, A.A., Maldenov, K. and Meyer, D.C. (2007) Anteroposterior Pelvic Radiographs to Assess Acetabular Retroversion: High Validity of the “Cross-over-Sign”. Journal of Orthopaedic Research, 25, 758-765. http://dx.doi.org/10.1002/jor.20380

[18] Tannast, M., Siebenrock, K.A. and Anderson, S.E. (2007) Femoroacetabular Impingement: Radiographic Diagnosis-What the Radiologist Should Know. American Journal of Roentgenology, 188, 1540-1552. http://dx.doi.org/10.2214/AJR.06.0921

[19] Siebenrock, K.A., Kalbermatten, D.F. and Ganz, R. (2003) Effect of Pelvic Tilt on Acetabular Retroversion: A Study of Pelves from Cadavers. Clinical Orthopaedics and Related Research, 407, 241-248. http://dx.doi.org/10.1097/00003086-200302000-00033

[20] Karashima, H., Naito, M., Shiramizu, K., Kiyama, T. and Maeyama, A. (2011) A Periacetabular Osteotomy for the Treatment of Severe Dysplastic Hips. Clinical Orthopaedics and Related Research, 469, 1436-1441. http://dx.doi.org/10.1007/s11999-010-1616-x

[21] Kiyama, T., Naito, M., Shiramizu, K. and Shinoda, T. (2009) Postoperative Acetabular Retroversion Causes Posterior Osteoarthritis of the Hip. International Orthopaedics, 33, 625-631. http://dx.doi.org/10.1007/s00264-007-0507-6

[22] Siebenrock, K.A., Scholl, E., Lottenbach, M. and Ganz, R. (1999) Bernese Periacetabular Osteotomy. Clinical Orthopaedics and Related Research, 363, 9-20. http://dx.doi.org/10.1097/00003086-199906000-00003

[23] Steppacher, S.D., Tannast, M., Ganz, R. and Siebenrock, K.A. (2008) Mean 20-Year Follow-Up of Bernese Periacetabular Osteotomy. Clinical Orthopaedics and Related Research, 466, 1633-1644. http://dx.doi.org/10.1007/s11999-008-0242-3

[24] Hack, K., Di Primio, G., Rakhra, K. and Beaule, P.E. (2010) Prevalence of Cam-Type Femoroacetabular Impingement Morphology in Asymptomatic Volunteers. The Journal of Bone and Joint Surgery (American Volume), 92, 2436-2444. http://dx.doi.org/10.2106/JBJS.J.01280

[25] Mori, R., Yasunaga, Y., Yamasaki, T., Nakashiro, J., Fujii, J., Terayama, H., Ohshima, S. and Ochi, M. (2014) Are Cam and Pincer Deformities as Common as Dysplasia in Japanese Patients with Hip Pain? The Journal of Bone and Joint Surgery (British Volume), 96, 172-176. http://dx.doi.org/10.1302/0301-620X.96B2.32680

[26] Agricola, R., Heijboer, M.P., Bierma-Zeinstra, S.M.A., Verhaar, J.A.N., Weinans, H. and Waarsing, J.H. (2013) Cam Impingement Causes Osteoarthritis of the Hip: A Nationwide Prospective Cohort Study (CHECK). Annals of the Rheumatic Disease, 72, 918-923. http://dx.doi.org/10.1136/annrheumdis-2012-201643

[27] Albers, C.E., Steppacher, S.D., Ganz, R., Tannast, M. and Siebenrock, K.A. (2013) Impingement Adversely Affects 10-Year Survivorship after Periacetabular Osteotomy for DDH. Clinical Orthopaedics and Related Research, 471, 1602-1614. http://dx.doi.org/10.1007/s11999-013-2799-8

[28] Nakayama, H., Fukunishi, S., Fukui, T. and Yoshiya, S. (2014) Arthroscopic Labral Repair Concomitantly Performed 
with Curved Periacetabular Osteotomy. Knee Surgery, Sports Traumatology, Arthroscopy, 22, 938-941. http://dx.doi.org/10.1007/s00167-013-2362-x

[29] Clohisy, J.C., Carlisle, J.C., Trousdale, R., Kim, Y.J., Beaule, P.E., Morgan, P., Steger-May, K., Schoenecker, P.L. and Millis, M. (2009) Radiographic Evaluation of the Hip Has Limited Reliability. Clinical Orthopaedics and Related Research, 467, 666-675. http://dx.doi.org/10.1007/s11999-008-0626-4 